\title{
Sequential nailfold capillary microscopy in scleroderma and related disorders
}

\author{
M L WONG, J HIGHTON, AND D G PALMER \\ From the Rheumatic Diseases Unit, Department of Medicine, University of Otago Medical School, Dunedin, \\ New Zealand
}

SUMMARY Sequential nailfold capillary microscopy was carried out monthly for seven months in seven patients (four with scleroderma, one with dermatomyositis, one with mixed connective tissue disease, and one with limited connective tissue disease). Progressive enlargement of some capillary loops was observed, with a number becoming obliterated, leaving avascular areas. Extravasation from capillaries usually preceded capillary loss. These observations have shown the progressive nature of the nailfold capillary abnormalities associated with these disorders and suggest that capillary enlargement is the result of injury, rather than compensation for capillary loss.

A characteristic pattern of nailfold capillary abnormalities is seen in most patients with scleroderma (SD), dermatomyositis (DM), and mixed connective tissue disease (MCTD). ${ }^{1-3}$ These abnormalities typically comprise enlarged capillary loops and areas of avascularity, but may also include bushy capillaries and disorganisation of the normal regular pattern of capillaries. The extent of avascular change has been correlated with disease duration. ${ }^{45}$ Although this would suggest that the capillary changes are progressive, previous studies have not primarily addressed this question. In this paper we describe the sequen-

Accepted for publication 19 June 1987.

Correspondence to Professor D G Palmer. Wellcome Medical Research Institute. PO Box 913. Dunedin. New Zealand. tial microscopic changes observed by low power microscopy in the nailfold capillaries of patients with $\mathrm{SD}$ and related disorders.

\section{Patients and methods}

\section{PATIENTS}

Seven patients attending the rheumatic diseases unit, Dunedin Hospital, Dunedin, New Zealand, were studied. The diagnostic groups included four with SD, one with DM, one with MCTD, and one with a limited connective tissue disease syndrome (LCTD). ${ }^{6}$ Diagnosis of SD was based on the American Rheumatism Association criteria. ${ }^{7}$ The clinical characteristics of the patients are summarised in Table 1.

Table 1 Clinical characteristics and nailfold capillary changes in patients with scleroderma and related disorders

\begin{tabular}{|c|c|c|c|c|c|c|c|}
\hline $\begin{array}{l}\text { Patient } \\
\text { No }\end{array}$ & $\begin{array}{l}\text { Age } \\
\text { (years) }\end{array}$ & Sex & Diagnosis & $\begin{array}{l}\text { Duration of } \\
\text { Raynaud's } \\
\text { phenomen } \\
\text { (years) }\end{array}$ & Skin changes* & $\begin{array}{l}\text { Mean No of } \\
\text { enlarged } \\
\text { loops per } \\
\text { digit }\end{array}$ & $\begin{array}{l}\text { Mean } \\
\text { avascular } \\
\text { score per } \\
\text { digit' }\end{array}$ \\
\hline 1 & 4() & $\mathrm{F}$ & SD & 8 & + & $8 \cdot 5$ & $1 \cdot 5$ \\
\hline 2 & 68 & $\mathbf{F}$ & $\mathrm{SD}$ & 5 & ++ & 5 & $1 \cdot 5$ \\
\hline 3 & 50 & $\mathrm{M}$ & $\mathrm{SD}$ & 10 & ++ & $1 \cdot 6$ & 0.9 \\
\hline 5 & 56 & $\mathbf{F}$ & $\mathrm{DM}$ & 7 & + & 4.9 & 1.9 \\
\hline 6 & 39 & $\mathrm{M}$ & MCTD & 10 & + & $6 \cdot 3$ & $1 \cdot 5$ \\
\hline 7 & 34 & $F$ & LCTD & 2 & Nil & 2 & $0 \cdot 5$ \\
\hline
\end{tabular}

$*+=$ sclerodactyly. $++=$ proximal scleroderma.

$\doteqdot$ Semiquantitative assessment. ${ }^{\dagger}$ 
NAILFOLD CAPILLARY MICROSCOPY

In each patient the nailfolds of all eight fingers (excluding the thumbs) were examined under a Zeiss DRC stereomicroscope after application of a drop of immersion oil. Photography was carried out with a Nikon FE single lens reflex camera body and Agfa ortho 25 professional black and white film. The final magnification on the negative was six times and all prints were examined at a final magnification of 42 times. Microscopy was carried out in each patient at monthly intervals from April to Octob市 1986 (southern hemisphere-autumn, winter, arad

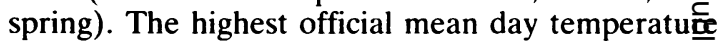
for the Dunedin city area during the period of stue. was $13.3^{\circ} \mathrm{C}$ and the highest recorded temperatuge was $26.4^{\circ} \mathrm{C}$ (April). The lowest mean day temperi⿱⺈-

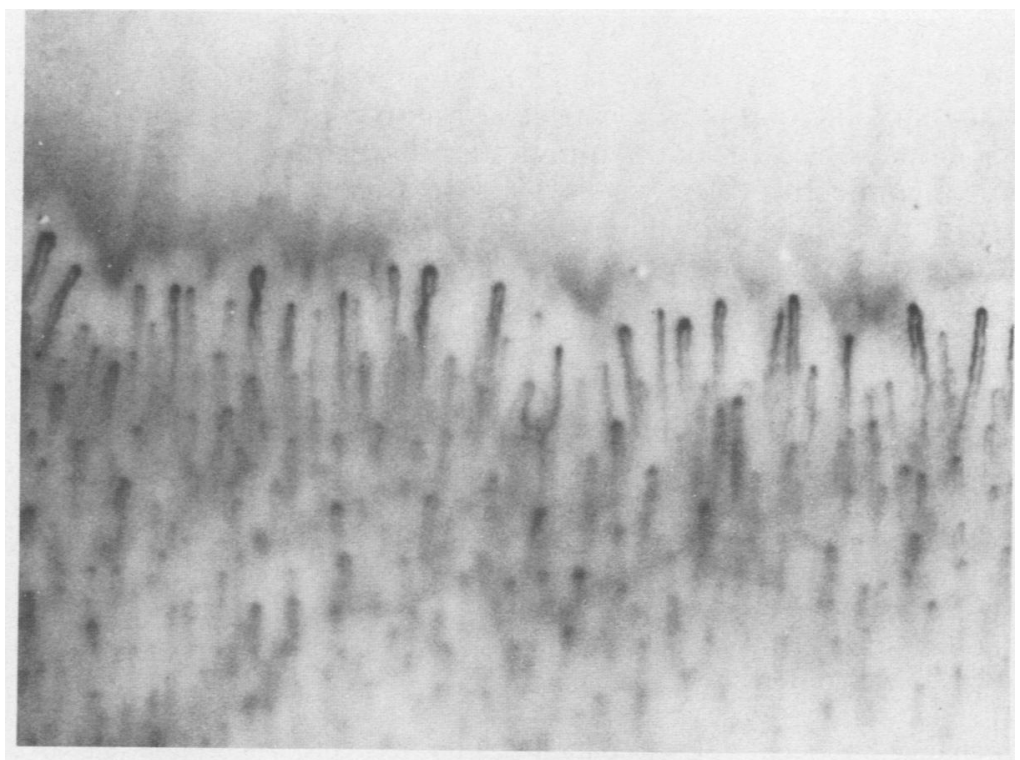

(a)

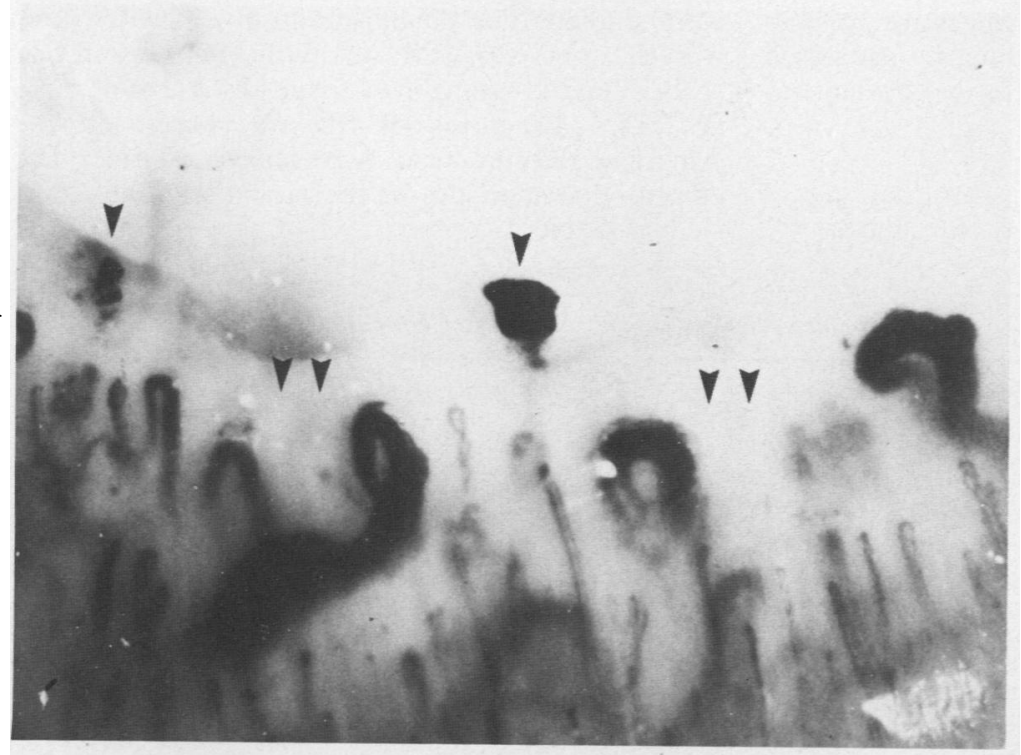

(b)
Fig. 1 (a) Normal nailfold capillary pattern in a control subject. (b) Classic pattern of enlarged loops and avascular areas in the patient with DM (No 5). Note the advanced giant loop formation, avascular areas (doub arrows), and extravasates (single arrows). 
ture was $6.8^{\circ} \mathrm{C}$ and the lowest recorded was $-2 \cdot 5^{\circ} \mathrm{C}$ (August). In two patients (Nos 5 and 7) additional microscopy was carried out weekly for three weeks during September (early spring).

Nailfold photographs were carefully examined for enlarged loops and avascular areas by the semiquantitative method of assessment described by Lee $e t$ al. ${ }^{4}$ Photographs of each digit were arranged in sequence and analysed for changes with time. Capillary loop changes were said to have taken place only if they were observed in at least two separate sequential photographs of satisfactory technical quality and were agreed upon by all three authors.

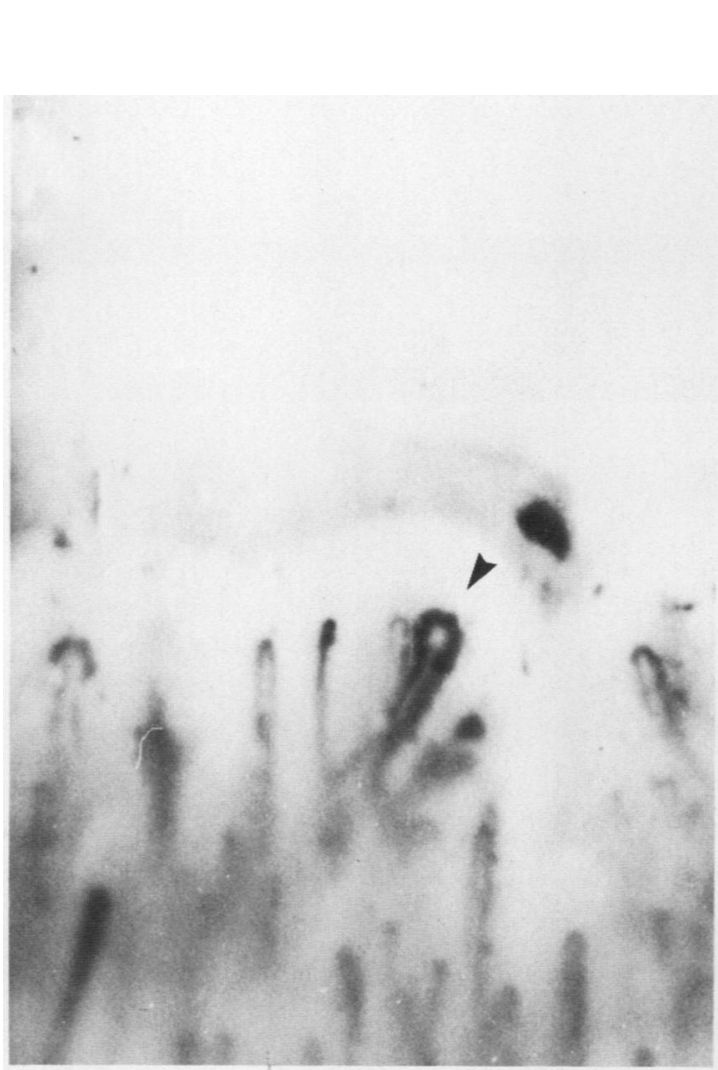

(a)

Fig. 2 Sequential microvascular changes at intervals of eight weeks in the patient with DM (No 5). The capillary bed as a whole has changed considerably during the observation period with a changing pattern of extravasate. (a) An enlarged capillary loop (arrow) with two adjacent normal sized capillaries to the immediate left.

(b) Progressive enlargement of two of thes ' 'ops (arrow).

(c) The initial enlarged loop has become. ." 'rated leaving an avascular area, but a remnant is visible $(a, w)$ which is probably a thrombosed and occluded segmeni. Further loops to the left have become enlarged.

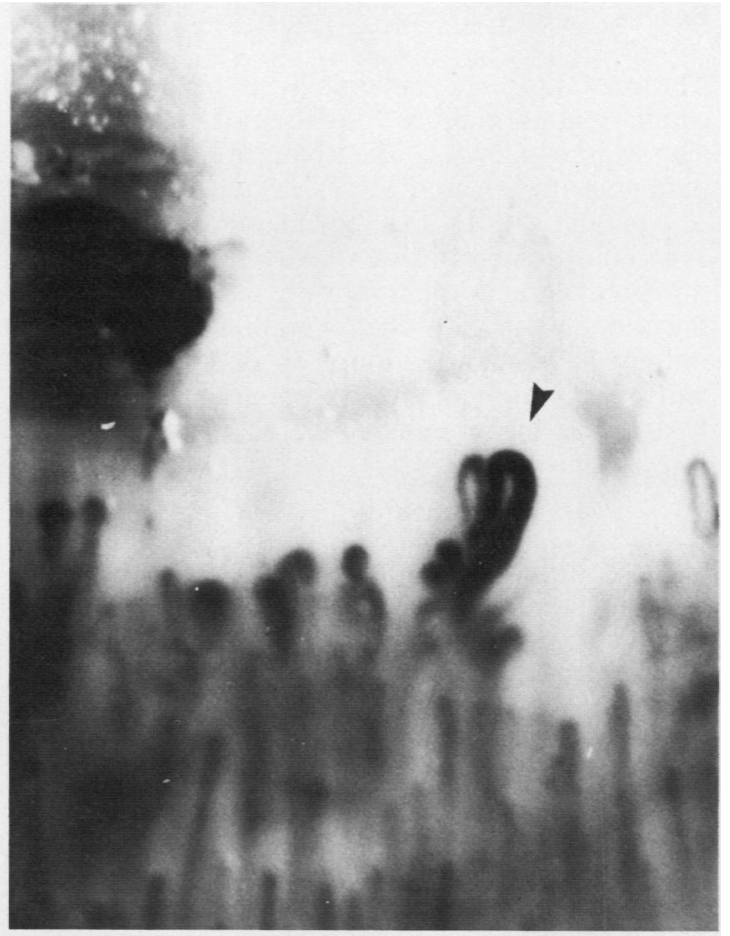

(b)

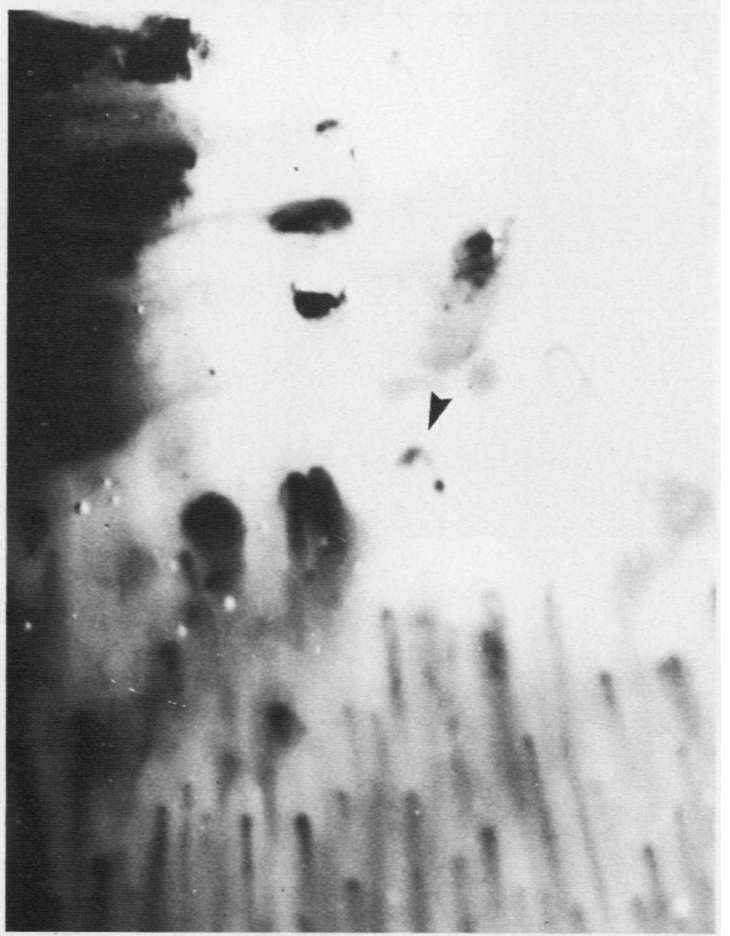

(c) 


\section{Results}

Three of the four patients with SD had typical capillary abnormalities consisting of enlarged loops and avascular areas. The changes associated with patients with DM and MCTD were similar (Fig. 1). The patient with LCTD had enlarged capillaries and avascular areas consistent with the SD pattern, though these abnormalities were not as marked as in the patients with SD. The remaining patient with SD did not have enlarged loops or avascular areas but had prominent subpapillary plexuses in most nailfolds. The mean number of enlarged loops and

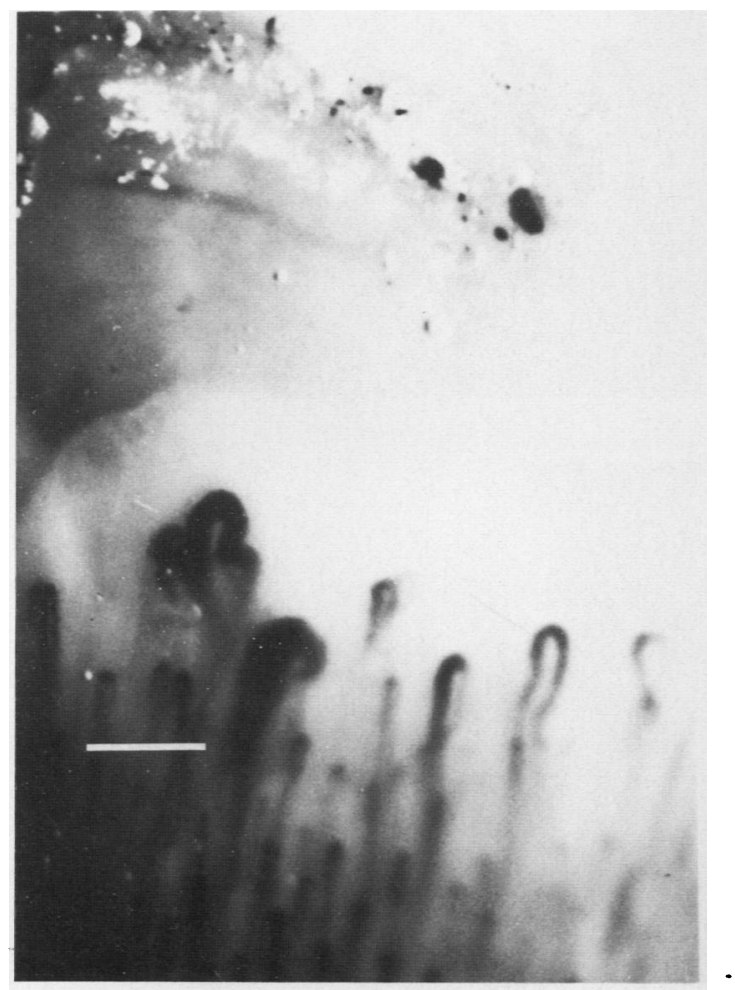

(a)

Fig. 3 Loss and redevelopment of giant loops in the patient with DM (No 5). Three capillary loops which remained unchanged through the period of observation are indicated by a bar for reference. (a) Two grossly enlarged capillaries (left) which had remained the same size for four months. (b) Two weeks later both loops have become obliterated with the appearance of extravasations distally in the cuticle. (c) The reappearance of giant loops after a further interval of two months. Note that these appear to have developed from vessels lying deeply to the most distal capillary array visible in (b).

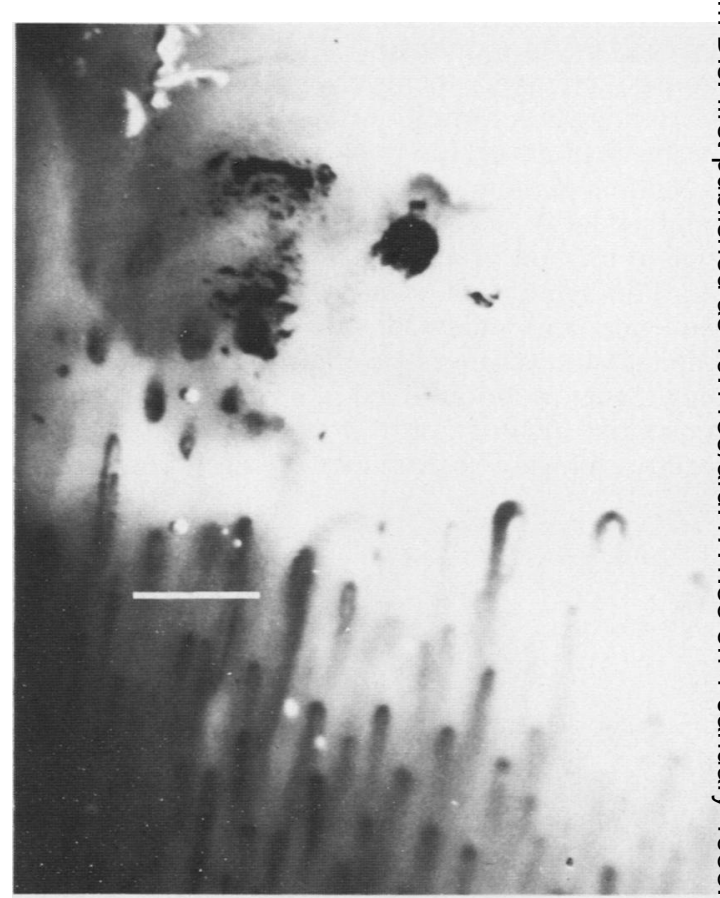

(b)

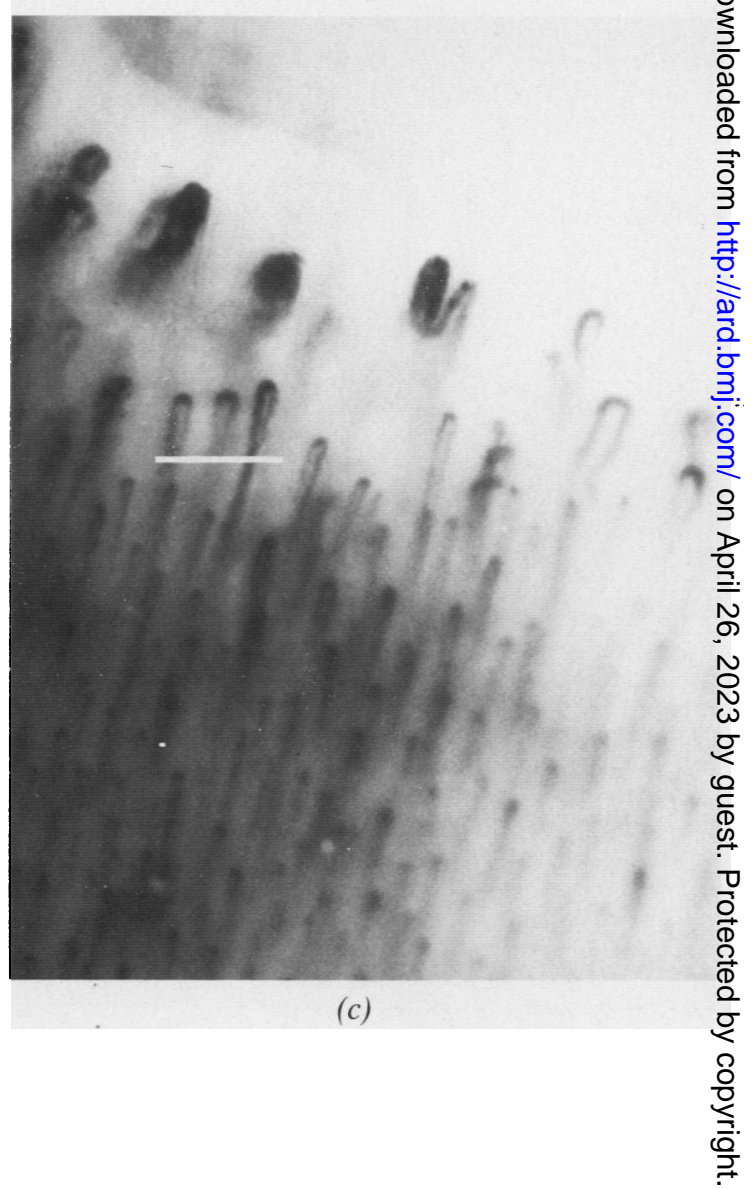




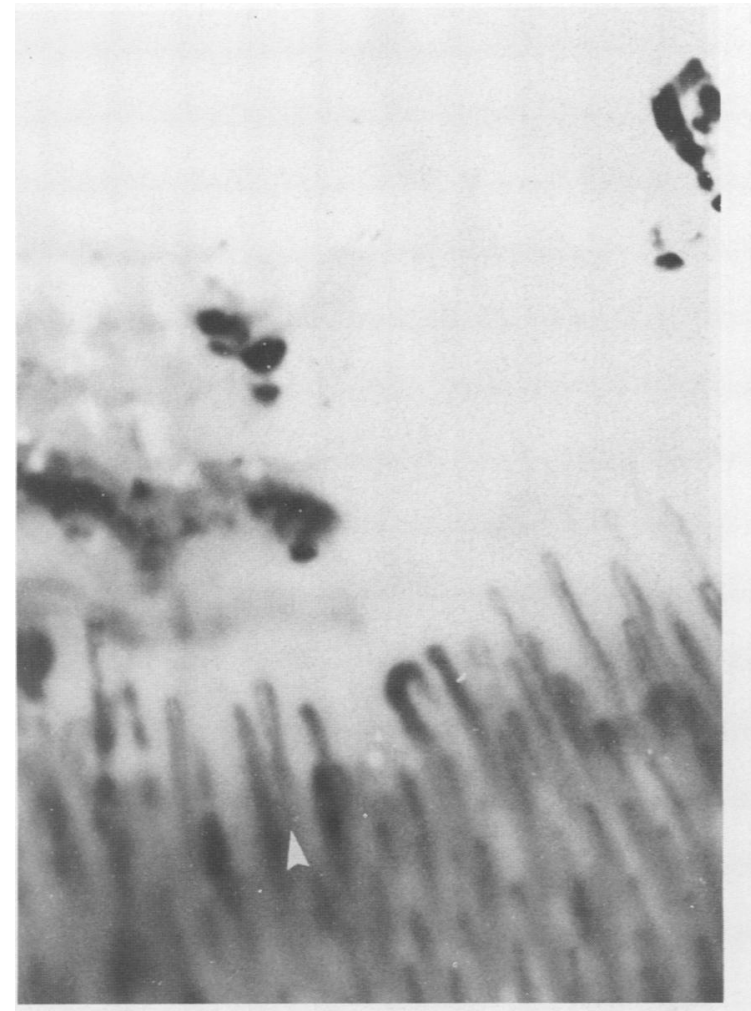

(a)

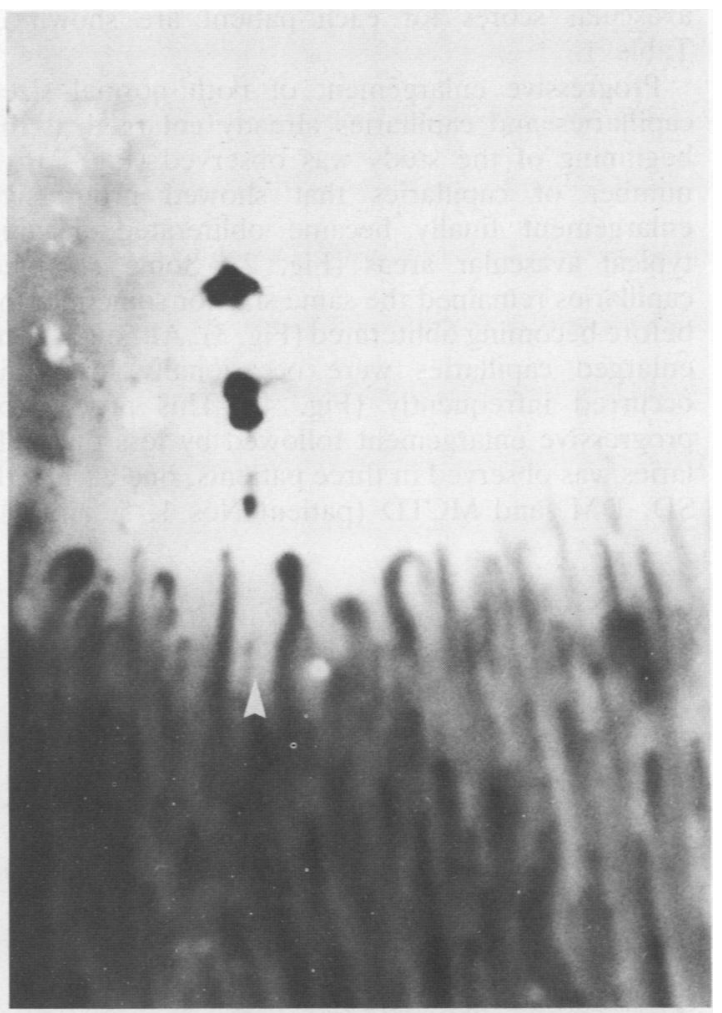

(b)

Fig. 4 Example of a non-enlarged capillary loop lost within four weeks in the patient with MCTD (No 6). (a) Nonenlarged capillary loop (arrow). (b) Loop obliterated with three separate extravasations in alignment distally (arrow). Acute capillary enlargement during the intervening four week period cannot be excluded.

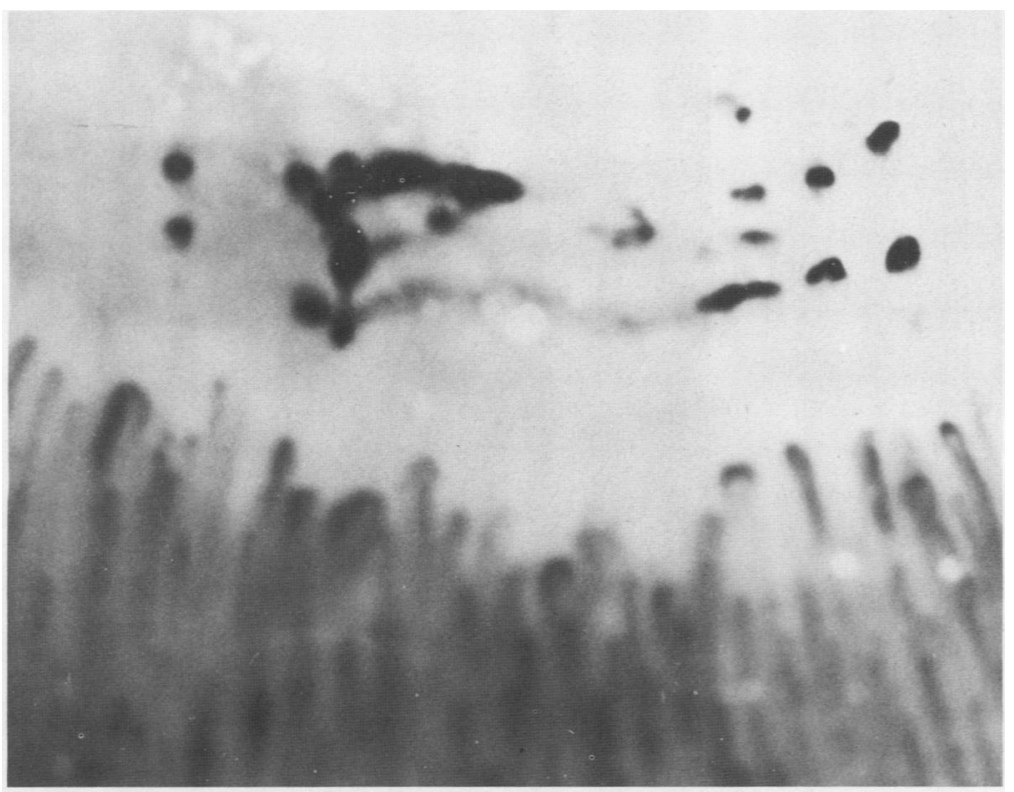

Fig. 5 Intermittent and synchronous extravasation in the patient with MCTD (No 6). Extravasations in the cuticle showing both transverse and longitudinal disposition of extravasates indicative of intermittent and synchronous leakage from multiple capillary loops. Note the alignment of the capillary loops and corresponding extravasates. 
avascular scores for each patient are shown in Table 1.

Progressive enlargement of both normal sized capillaries and capillaries already enlarged at the beginning of the study was observed (Fig. 2). A number of capillaries that showed progressive enlargement finally became obliterated, leaving typical avascular areas (Fig. 2). Some enlarged capillaries remained the same size for some months before becoming obliterated (Fig. 3). Although nonenlarged capillaries were occasionally lost, this occurred infrequently (Fig. 4). This process of progressive enlargement followed by loss of capillaries was observed in three patients, one each with SD, DM, and MCTD (patient Nos 1, 5, and 6).

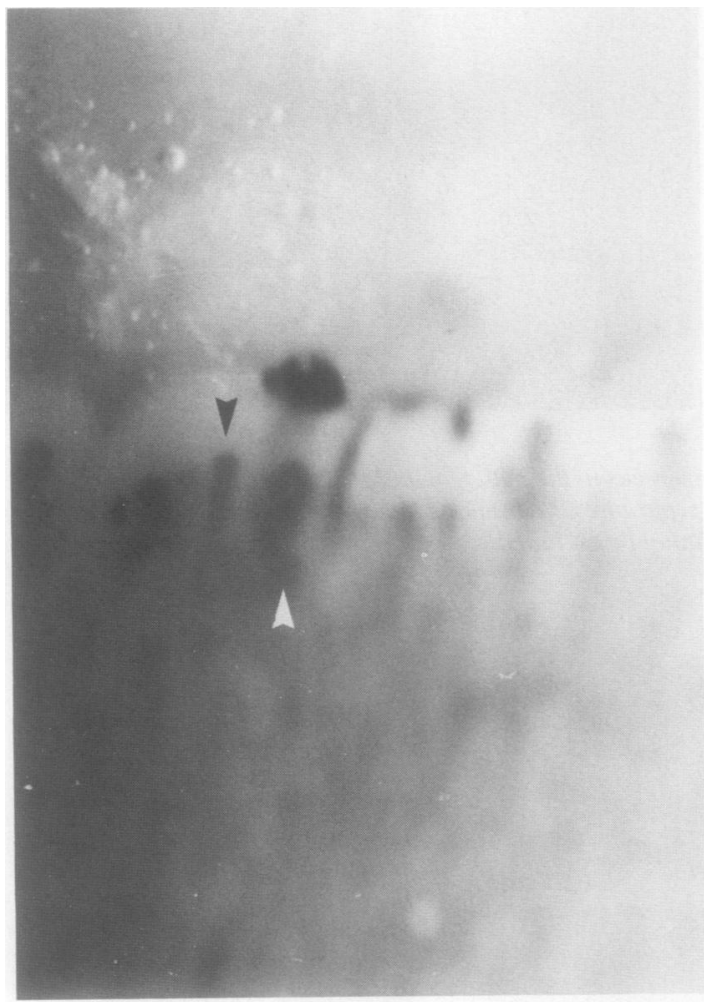

\section{(a)}

Fig. 6 Progressive loss of a capillary loop associated with multiple sequential extravasates in the patient with DM (No 5). (a) Extravasation from an enlarged loop (white arrow). (b) Recurring episodes of extravasation as this loop is obliterated through a further four weeks. (c) Loss of the capillary after another four weeks. Immediately to the left of the capillary loop that is lost is a loop which progressively enlarges through this series (black arrows) and which was also subsequently lost (not shown). Two further loops have enlarged in mid-field.

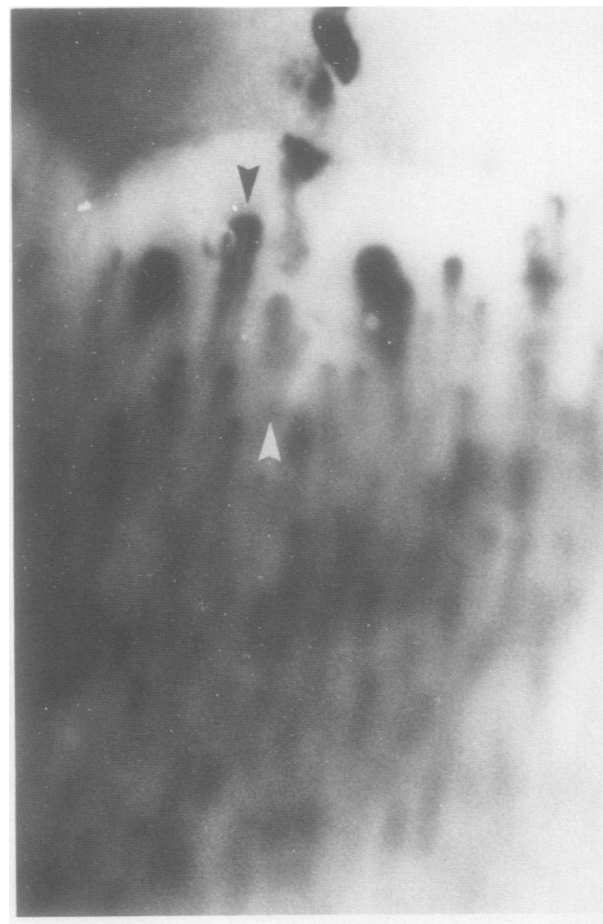


Another prominent feature was evidence of recurrent episodes of extravasation from capillary loops, seen as deposits lying within the nail cuticle immediately distal to the involved capillary. Distal migration of the deposits, followed by further episodes of extravasation, sometimes gave rise to a 'beaded' appearance (Figs 4, 5, and 6). In some cases extravasation from multiple independent capillary loops led to rows of beaded extravasates which sometimes fused to form transverse lines in the cuticle (Fig. 5). Extravásations were more frequently associated with enlarged capillaries than with those of normal size.

Loss of a capillary loop was often heralded by episodes of extravasation (Fig. 6). When loss of a capillary did occur without extravasation having been visible in direct apposition to the involved loop, evidence of an earlier episode of extravasation could usually be found in the nailfold cuticle distal to the site from which the capillary had been lost (Figs 3 and 4). Most episodes of extravasation, however,

were not associated with capillary obliteration during the period of observation.

Deformities of capillaries producing a bushy appearance were also seen. In one instance, one capillary loop in a group of four developed a bushy appearance. This was associated with recurrent episodes of extravasation from the three adjacent capillaries terminating in their loss, leaving the remaining capillary loop altered to a bushy form (Fig. 7).

\section{Discussion}

The presence of enlarged nailfold capillaries in SD was noted more than 60 years ago by Brown and O'Leary, who suggested that these enlarged loops 'may be a pathologic state related to the fibrotic changes in the corium, that is, back pressure effects' ${ }^{8}$ They thought that the enlarged capillaries were less likely to represent simple hypertrophy, though Redisch et al and Rouen et al subsequently

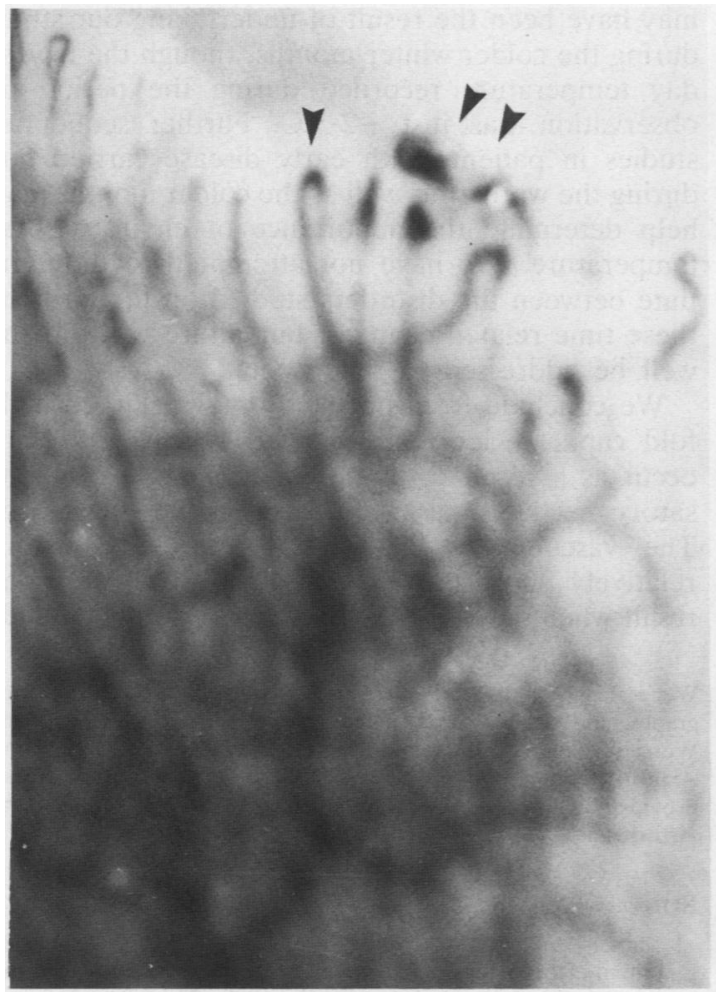

(a)

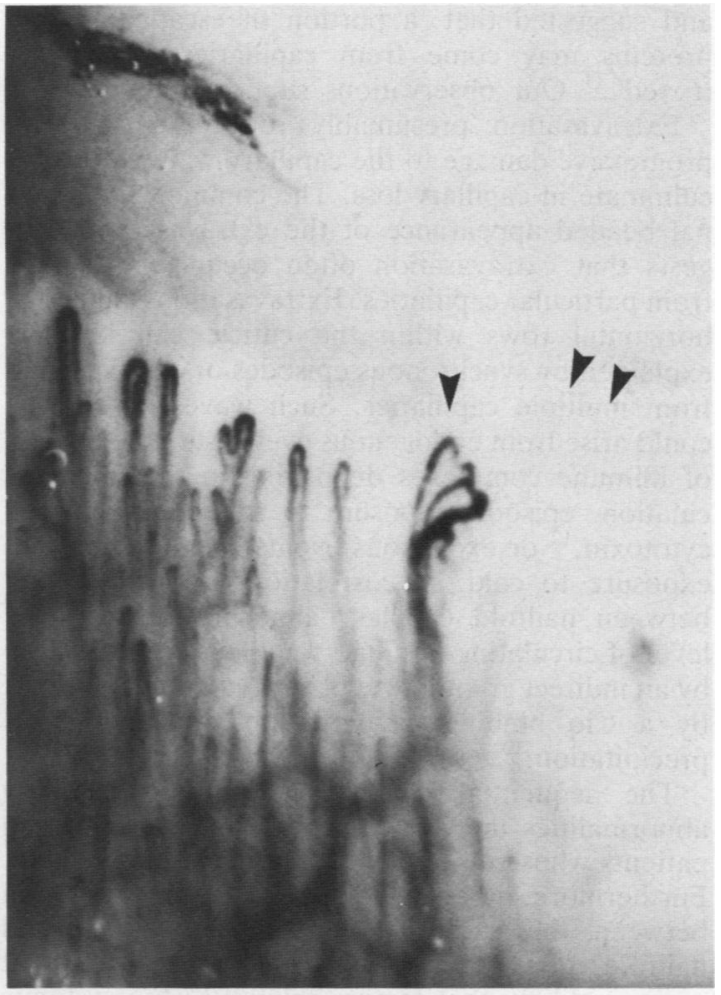

(b)

Fig. 7 Bush formation in the patient with DM (No 5). (a) Single loop (vertical arrow) flanked on the right by three other loops with associated extravasates (oblique arrows). (b) Two months later the single loop has formed a bush (vertical arrow) and the extravasating loops have been lost (oblique arrows). 
favoured the idea that the capillary loops enlarge to compensate for the loss of other capillaries. ${ }^{910} \mathrm{Our}$ study has shown that capillary loops often enlarge before becoming obliterated, and that enlarged loops are more prone both to extravasations and loss than are non-enlarged loops. This suggests that capillary enlargement is a consequence of capillary injury. If enlarged capillaries do represent a compensatory mechanism, our findings might be explained by postulating that 'hypertrophied' loops are more prone to damage than non-enlarged loops. We did, however, also observe numbers of enlarged capillaries, including giant loops, which remained unchanged without extravasation or loss during the whole study period despite adjacent enlarged loops undergoing further sequential changes. Thus we favour the view that capillary enlargement is most likely the result of mural damage.

Capillary loops that finally underwent obliteration usually appeared to first leak extravasate. Thompson et al found a correlation between the degree of capillary loss and the amount of plasma protein deposited in the involved nailfold cuticles and suggested that 'a portion of escaped plasma proteins may come from capillaries being destroyed'. ${ }^{11}$ Our observations support this view.

Extravasation presumably reflects a stage in progressive damage to the capillary wall which may culminate in capillary loss. The common longitudinal beaded appearance of the extravasations suggests that extravasation often occurs episodically from particular capillaries. Extravasations aligned in horizontal rows within the cuticle can best be explained by synchronous episodes of extravasation from multiple capillaries. Such waves of damage could arise from endogenous events such as showers of immune complexes depositing in the microcirculation, episodic exposure to an endothelial cell cytotoxin, ${ }^{12}$ or exogenous events such as recurrent exposure to cold. A correlation has been found between nailfold capillary abnormalities and the level of circulating immune complexes as measured by an indirect granulocyte phagocytosis test, but not by a Clq binding assay or polyethylene glycol precipitation. ${ }^{13}$

The sequential changes in nailfold capillary abnormalities that we observed, however, were in patients whose disease was in other respects stable. Furthermore, others have not found any correlation between the extent of organ involvement and nailfold capillary abnormalities. ${ }^{245}$ Therefore, it seems unlikely that factors related to the systemic disease are alone responsible for the observed nailfold changes. In a rat model of microvascular inflammation and superimposed cold injury, Kulka observed in sequence, venular dilatation, extravasa- tion from venules and capillaries, thrombosis an occlusion, and finally, vascular obliteration. ${ }^{14}$ This series of events is remarkably similar to those we have observed, including loop obliteration. Kullo suggested that thrombosis could be brought abot by stasis secondary to vascular dilatation and in creased blood viscosity due to excessive capillarơ leakage. Our observation that episodes of extravas $\overrightarrow{5}$ tion precede capillary loss is compatible with this hypothesis. It seems that a likely explanation for the sequential changes we observed in the affected nailfold capillaries could be the effect of cold injur or other exogenous events, superimposed upot endogenous vascular injury.

The presence of bushy capillaries has been attrig buted to budding of capillaries in attempteed revascularisation. ${ }^{4}$ Our observation of the evolution of a bush after the loss of three adjacent capillafy loops is consistent with this view.

Maricq and Spencer-Green et al have stated th nailfold capillary abnormalities are stable and do not change with time. ${ }^{15} 16$ We observed sequentif changes at intervals of no more than a month. These may have been the result of undertaking our study during the colder winter months, though the lowest day temperature recorded during the period 8 observation was just $-2 \cdot 5^{\circ} \mathrm{C}$. Further sequentiogl studies in patients with early disease carried ogt during the warmer as well as the colder months may help determine the importance of environment? temperature. We have not attempted to differentiate between the disorders studied on the basis of these time related changes, but future work might well be addressed to this aspect.

We conclude from our study that enlarged naisfold capillary loops in SD and related disorderts occur as a result of injury, and not as a compegsatory mechanism as has been previously suggested. The vasculopathy is overtly progressive with relatively short time spans, and avascular areas result when damaged capillaries become obliterate

N

We wish to thank Mr Brian Connor for assistance with photggraphy, and Mrs Joan McKenna for typing the manuscript. Dr MS Wong was in receipt of the Tom Highton Fellowship from th Arthritis Foundation of New Zealand. Financial support was provided by the Medical Research Council of New Zealand and the Arthritis Foundation of New Zealand.

\section{References}

1 Maricq H R, LeRoy E C, D'Angelo W A, et al. Diagnos potential of in vivo capillary microscopy in scleroderma afo related disorders. Arthritis Rheum 1980; 23: 183-9.

2 Kenik J G, Maricq H R, Bole G G. Blind evaluation of the diagnostic specificity of nailfold capillary microscopy in the connective tissue diseases. Arthritis Rheum 1981; 24: 885-9

3 Granier F, Vayssairat M, Priollet P, Housset E. Nailfogd capillary microscopy in mixed connective tissue disease: com- 
parison with systemic sclerosis and systemic lupus erythematosus. Arthritis Rheum 1986; 29: 189-95.

4 Lee P, Leung F Y K, Alderdice C, Armstrong S K. Nailfold capillary microscopy in the connective tissue diseases: a semiquantitative assessment. $J$ Rheumatol 1983; 10: 930-8.

5 Lovy M, MacCarter D, Steingerwald J C. Relationship between nailfold capillary abnormalities and organ involvement in systemic sclerosis. Arthritis Rheum 1985; 28: 496-501.

6 Palmer D G, Hale G M, Grennan D M, Pollock M. Bowed fingers. A helpful sign in the early diagnosis of systemic sclerosis. J Rheumatol 1981; 8: 266-72.

7 Subcommittee for Scleroderma Criteria of the American Rheumatism Association Diagnostic and Therapeutic Criteria Committee. Preliminary criteria for the classification of systemic sclerosis (scleroderma). Arthritis Rheum 1980; 23: $581-90$

8 Brown G E, O'Leary P A. Skin capillaries in scleroderma. Arch Intern Med 1925; 36: 73-88.

9 Redisch W, Messina E J, Hughes G, McEwen C. Capillaroscopic observations in rheumatic diseases. Ann Rheum Dis 1970; 29: 244-53.
10 Rouen L R, Terry E N, Doft B H, Clauss R H, Redisch W. Classification and measurement of surface microvessels in man. Microvasc Res 1972; 4: 285-92.

11 Thompson R P, Harper F E, Maize J C, Ainsworth S K, LeRoy E C, Maricq H R. Nailfold biopsy in scleroderma and related disorders: correlation of histologic capillaroscopic, and clinical data. Arthritis Rheum 1984; 27: 97-103.

12 Jayson M I V. Systemic sclerosis: a collagen or microvascular disease? $\mathrm{Br}$ Med J 1984; 288: 1855-7.

13 Houtman P M, Kallenberg C G M, Wouda A A, The T H. Decreased nailfold capillary density in Raynaud's phenomenon: a reflection of immunologically mediated local and systemic vascular disease? Ann Rheum Dis 1985; 44: 603-9.

14 Kulka J P. Microcirculatory impairment as a factor in inflammatory tissue damage. Ann NY Acad Sci 1964; 116: 1018-44.

15 Maricq H R. Widefield capillary microscopy: technique and rating scale for abnormalities seen in scleroderma and related disorders. Arthritis Rheum 1981; 24: 1159-65.

16 Spencer-Green G, Crowe W E, Levinson J E. Nailfold capillary abnormalities and clinical outcome in childhood dermatomyositis. Arthritis Rheum 1982; 25: 954-8. 